\title{
Introducing a Cross-Functional, Customer-Oriented IT-Cooperation-Model Supplementing ITIL
}

\author{
Jochen Hagen \\ Fielmann AG, Germany \\ jochen.hagen@fielmann.com
}

Justus T. Holler

Fielmann AG, Germany

jusuts.holler@fielmann.com

\author{
Michael Reimpell \\ Fielmann AG, Germany \\ michael.reimpell@fielmann.com \\ Marius Schlage \\ Fielmann AG, Germany \\ marius.schlage@fielmann.com \\ Malte Schroller \\ Fielmann AG, Germany \\ malte.schroller@fielmann.com
}

Purpose: Organising the processes of an IT department based on the ITIL framework is a common practice within companies that seek effective and efficient management of their IT incidents and problems. Although ITIL gives structure and guidance to a certain extent, we discovered several issues which were not optimally covered by the blueprint ITIL best practice processes that we are using. Therefore, we designed the "IT-Cooperation-Model" following a Design Science approach to tackle these specific issues. It is intended to supplement the established ITIL processes (in particular the incident and problem management) in a manner that these "cases" which need attention and are raised by one or more affected persons are handled by the most fitting, autonomous team in a highly collaborative manner to achieve customer satisfaction ultimately. Therefore, it was designed based on guiding principles to address and possibly overcome known and common issues in a predominant ticketbased system. This paper describes the motivation and perceived limitations in the pure ITIL processes that led to the IT-Cooperation-Model. We discuss the building principles, the instantiation and the mechanics we employed to continuously improve the model based on retrospectives and surveys, including feedback from customers and participants from previous cases.

Study design/methodology/approach: Design of an IT operational model based on a Design Science approach.

Findings: Cross-functional team collaboration within the designed operational model improved problem transparency, communication and ownership.

Originality/value: Newly designed IT operational model for managing issues that need attention and cannot be dealt with immediately or addressed appropriately, supplementing standard ITIL processes.

\section{Introduction}

The setting of the paper is a centralised IT department located in Germany which offers its capabilities to one of the most prominent multinational optometric and acoustic company groups worldwide with about 900 retail stores across Europe and various digital sales channels (online shops, apps etc.). The focused IT department supports the complete retail network and partly supports the production facilities and the core enterprise processes with its planning, building, and operating capabilities. This includes both the materials management processes and the associated fiscal process chain. An in-house-developed order management system furthermore increases the system-related complexity. 
This resulted in an overall system that can only be operated with great effort and cannot easily be developed further in short cycles. At that time, it was run in a traditional ITIL oriented setup containing service management, tickets handled by a three-stage organisation to address upcoming issues, and a topic-separated line organisation that distinguishes between plan, build and run.

The baseline process management approaches were based on ITIL v3 (What is ITIL | IT service management, 2021) blueprints partly adapted to fit specific requirements and organisational needs. The process management approaches for requirements, incident and problem management had to be re-evaluated to achieve higher efficiency in handling about 100,000 tickets per year. Although most of the tickets were handled promptly and customer satisfaction was at a high level, some tickets were not handled in the best possible way, and the issues appeared to be systematic.

To mitigate this strategic and situational challenge, it became evident that the process time cycles of addressing an issue had to be reduced. The possibility to respond had to move from static line-oriented to flexible and more agile.

Even more, under these circumstances, the number of new and unforeseen challenges increased significantly, requiring a much more flexible approach. By flexibility, it is meant that there are no existing or pre-thought processes or organisational units addressing the problem at hand. Thus, finding the right persons to involve, analysing the problem and even finding the right questions to ask are part of the task.

The henceforth-developed IT-Cooperation-Model was defined and specified in multiple iterations. It has been operational since 2019 and constitutes a customised solution to overcome the described challenges of flexibility and speed but also adhere to the legacy systems and respective supporting organisations that ensure the day-to-day business of a medium-sized international enterprise.

\section{Related Work}

\section{Business Process Management and corresponding frameworks}

Business Process Management is defined as managing, transforming and improving organisational operations (Hammer, 2010). A business process is defined as a completely closed, time-logical sequence of activities required to work on a process-oriented relevant business object (Becker \& Kahn, 2011, S. 6; Becker \& Schütte, 2004, S. 107). To structure the processes of a company or parts of it, several frameworks give guidance with best practice blueprints for processes and organisational setups. The most common are the COBIT (COBIT, 2021) and the ITIL (What is ITIL | IT service management, 2021) framework.

\section{Business Roles}

An organisational role is briefly a semantic construct. It forms the basis for access rights and supports the division of labour by bundling a set of responsibilities that an individual can carry out. In general, specific employee assignments can easily be reassigned and rotated through multiple users (Sandhu et al., 2002). Furthermore, assigning appropriate roles to particular employees improves overall coordination and efficient collaboration, just as a basketball team plays better when positions are set (den Hengst \& de Vreede, 2004; Richardson \& Andersen, 1995). In our paper, we particularly use the concept of separation of responsibilities and mandates bound to specific roles. 


\section{Limitations and pain points of existing ITIL-only approach}

While introducing dedicated process management for the IT department, the ITIL framework (What is ITIL | IT service management, 2021) based on version 3 was used as the blueprint for the first setup. Although several processes were interpreted and tailored as the framework strongly suggests, we perceived poor customer experience based on the following pain points within a relevant number of tickets:

Ticket-ping-pong: Internal customers from departments called the help desk and reported a problem. They received a ticket number for future reference in cases where the problem could not be solved right away. This ticket was then routed through the IT Service Management Tool and was eventually solved and communicated to the customer. In this process, it was reassigned between several groups and different ticket owners in the second and third-level support. This made finding a solution time-consuming and limited the possibility of cross-team collaboration. In many cases, the incident could not be solved and was classified as part of a problem ${ }^{1}$ and was assigned to the problem management group.

Our ITIL setup tends to fall into a ticket ping-pong state whenever the task lies across the borders between departments or teams. That is, the responsibility of the task is transferred back and forth between different parties. This is especially true for non-sequential work, which relies heavily on cooperation and non-local or hard-to-localise work. A clear indicator for being in a ticket ping-pong state is that people cannot check the results of their own work. In this situation, a person is forced to reach out to another person, asking for the impact of their change. These communication hops make learning cycles and verifying step-by-step procedures more difficult (Peter Van den Spiegel et al., 2013). Moreover, they prohibit instant feedback and instant gratification and thus prevent us from getting better or even demotivating the people involved (Anand et al., 2009; Bessant \& Caffyn, 1997, 1997; Kaymaz, 2011; Peter Schneider \& Philip Scherer, 2020).

Therefore, a design goal of our approach is to minimise communication hops and thus minimise activation energy and communication cost in all situations.

Separation of Problem and Incident Management: We followed the ITIL recommendation to separate incidents from problems. Although the experts were the same, we had separate problem managers responsible for coordinating the elimination of problems.

This detached problem management from expertise and action and led us to do the same work multiple times. The problem manager had to identify the necessary experts again, and the experts had to reanalyse the related incidents in their root cause analysis.

Consequently, a design goal of our approach is to combine the fix of the impact with the fix of the cause, if applicable.

Similar problems arise when there are different processes for supposedly new requirements than malfunctions. From the user's point of view, the technology is not doing what it is supposed to do in both cases. But instead of focusing the work on remedial action, too often, a lot of effort went into the description and classification of the requirement, e.g. necessary resources or organisational and technical interdependencies. Furthermore, this classification was often expected to be done by the affected person, regardless of whether they could have known it.

Therefore, a design goal of our approach is to minimise the activation energy for the affected person and thus avoid any kind of up-front classification.

\footnotetext{
${ }^{1}$ A problem is defined as "a cause of one or more Incidents" (AXELOS, 2011)
} 
Misguiding incentives: We use typical key performance indicators (KPI) such as initial resolution rate and customer satisfaction in our ITIL setup. But herein lies a problem. Simple, easy-to-solve problems overly positively influence these KPIs. But these problems should be avoided altogether or solvable via self-service if they cannot be avoided (e.g., forgotten password). Our KPIs often did not take the sustainability of the solution into account. Even more, preventing something proactively before it has a negative impact leaves your performance unproven and with low visibility.

Hence, a design goal of our approach is to value prevention more than remedy.

Indirect communication: The division of labour and distributed responsibilities within our ITIL setup lead to indirect communication with the affected persons. The current expert may not be able to give a status of the overall incident and may only be able to analyse part of the incident when in contact with an affected person. Status communication is carried out at firstlevel support, which often cannot provide detailed status information.

Consequently, a design goal of our approach is to foster transparency and direct communication with affected persons.

Service Management as a proxy: Our ITIL setup included IT Service Management as an interface between IT and business units. IT Service Management coordinated the division of labour between run and change, or application management and ICT infrastructure management, respectively (it-processmaps, 2020). As a result of this indirectness, service management merely acted as a proxy, where the question from the business unit was received by someone different from the person who answered. In addition, it did not help with taking operational requirements into account during development. Even more, it increased the overhead for changes since another management group now had to be included.

Therefore, a design goal of our approach is to foster direct collaboration and local decisions.

\section{IT-Cooperation-Model}

Our IT-Cooperation-Model is intended for topics that need attention and cannot be dealt with immediately or addressed appropriately by other means. Each such topic will therefore constitute a "case". With each case, we aim to solve the case while improving communication, transparency, ownership, and cross-team collaboration in contrast to our previous approach.

\section{Guiding principles}

To achieve the design goals mentioned above and improve in the mentioned areas when processing these cases, we have used the following guiding principles:

1. low-threshold entry channel,

2. no transfer of responsibilities,

3. mandate and responsibility go hand in hand,

4. transparency and collaboration,

5. built-in learning cycles.

The low-threshold entry channel guiding principle is that it shouldn't be hard for these cases to catch attention. It shouldn't matter how a case came up nor the channel on which it arrived. The source of the case could be anyone or anything, be it an affected person, legislation, a hint from a service provider, or any other information source. The information channel at which the case arrives also could be anything from personal contact, web, telephone, E-Mail, etc. To ensure the lowest possible threshold for the entry channel, we disallow any hurdles, even if they 
are common in other models like ITIL (BMC, 2021; ISO, 2011). There is no forwarding to a third party, such as a hotline or a contact person. There is no upfront classification of the case required as there is a single process, in stark contrast to our ITIL implementation that differentiates between business problems, requirements and IT problems. There is no mandatory information required, and there is no precondition to be met. Therefore, if any of this is necessary for a solution to a case, it becomes part of the work for the case team. This means that e.g. finding the right question is part of the work to be done for the case. Finding the right contact persons is part of the work to be done for the case. Any former pre-analysis is part of the work to be done for the case.

However, as a low-threshold entry channel has the chance of being flooded with requests, some coordination must be established to funnel the requests into processing essentially. This is done by a coordination team that filters out non-case topics that can be addressed promptly or by an existing process to prioritise in case of conflict and, most importantly, to spawn a case team, which brings us to the following guiding principle: No transfer of responsibilities.

The guiding principle that there should be no transfer of responsibilities addresses the enormous costs of communication hops, be it increasing loss of information with the number of hops (Markey-Towler, 2017) or simply the time and communication effort required for a feedback cycle when multiple parties are involved. Having no transfer of responsibility also makes the clarification of responsibility as an activity obsolete and avoids redirection. Having no communication hops also makes the interaction with those affected more direct. In addition, one cannot evade one's responsibility, which closes retreat possibilities. To achieve this principle, a temporary cross-functional team is spawned for every case, including all required subject matter experts (SME). To avoid the problem of shared responsibility, one team member takes on the role of the "Red Hat" and is the person accountable for solving the case. However, the decision as to whether a case has been solved is also not transferred and can therefore only be made by an affected person. For the team to work on a case autonomously, unrestricted direct access to the necessary resources is required.

The guiding principle that mandate and responsibility go hand in hand allows the Red Hat to get unrestricted direct access to the organisation and their assets. In our implementation, this applies to IT only. As this overrules the line organisation's managers, Red Hat's role follows a pull principle so that anyone can take it. Therefore, line managers can essentially block the access of the case team to their department or department assets by taking the Red Hat role. However, this also makes them responsible for that case's solution, so a pure refusal is impossible. With finite resources, this still leads to resource allocation conflicts and requires prioritisation. The acceptance of this prioritisation is promoted by transparency and cooperation.

The guiding principle of transparency and collaboration is also common for other methodologies utilising cross-functional teams (Anderson, 2003; Juric, 2000; Ken Schwaber \& Jeff Sutherland, 2020). Transparency means that everyone has access to all crucial information, except for personal or other confidential data. For this, SMEs and affected persons are part of the case team so that they are all informed about the case status, get contextual knowledge, and are aware of the rationale behind decisions. Collaboration allows for continuous feedback and avoids unnecessary duplication of effort. Transparency and collaboration foster knowledge sharing and learning insights both from the case at hand and from other cases.

We have the guiding principle of built-in learning cycles to promote continuous improvement. After a case is solved, it is encouraged that the team takes the time to reflect on the lessons learned. For a case that stems from an error situation, a postmortem (Birk et al., 2002) is mandatory. It helps to identify underlying causes and weak spots that need improvement. In 
addition, regular retrospectives ensure a learning cycle over several cases and allow learning from the mistakes of others. For these learning cycles to be effective, management must continuously maintain psychological safety (Edmondson, 1999).

\section{Roles within the IT-Cooperation-Model}

For each case, a temporary cross-functional case team is initiated with the following roles:

- The affected person (client/customer) is the requester of the case or a stand-in. Ideally, this person is responsible for the process or system or capability that is the subject of the case, but this is not mandatory. This role can decide whether or not to process the request in the case. For this, the role helps to clarify the requirements and find solutions. In the end, the affected person checks whether the solution offered is satisfactory. The affected person thus decides whether a case can be closed.

- Red Hat's responsibilities include analysing and understanding the requirements and resolving the reason for the case to the satisfaction of the affected person. This also includes ensuring that the solution is quality assured. Until this is done, the case is pushed forward by this role. To do this, all hurdles are removed, and, if necessary, other staff members are involved in the case. In addition, the Red Hat ensures that the status and next steps of the case are transparent. For this, binding and scheduled communication are made in the case. This is one of the central tasks. A third party should always see from the case what the next steps are, who will carry them out and when they will be carried out. If the case falters or no solution is found, it is the responsibility of Red Hat to escalate the case to management. Any employee can fill the Red Hat. Every caseworker can occupy this role through simple, informal communication in the case. Usually, the Red Hat is close to the capability used in the case. If the capability changes, the Red Hat may possibly change as well. If it becomes apparent that the current Red Hat cannot solve the case or is not making progress, someone else should take over the Red Hat. The Red Hat can also be discarded and automatically taken over by a coordination team member.

- Case team: This temporary team can access all the capabilities of the entire IT organisation through the mandate of the Red Hat. Everyone involved in the case is part of the case team. Their task is to analyse the requirements of the stakeholder's request and formulate solution scenarios to manage the case from implementation to closure.

- Coordination Team member ("process manager"): The coordination team member is responsible for implementing and further developing the IT-Cooperation-Model. The Coordination Team forms an overarching body over all cases. The coordination team member is the central custodian of the methodology, observes how cases are handled and provides an impetus for changing the model or collaboration. They create the case and are the Red Hat at the beginning by default. Therefore, the coordination team member ensures that the drive in the case is created and maintained until someone else takes over the Red Hat. Furthermore, they represent the point of contact to give a status report on all cases. At the end of a case, they set up the retrospective and can also moderate if desired. Finally, the coordination team member collects findings and ensures that the results are sustainable and transparent.

- Team leads: The team leads are represented in the cases primarily to gain insights into which cases affect their area or their staff. These insights are the basis for creative participation in the planned retrospectives with all other IT team leads to develop the ITCooperation-Model further. 


\section{Technical and organisational installation}

To implement the IT-Cooperation-Model, we needed some technical communication framework. We started using Slack (Slack Technologies, 2021) as the primary communication channel for case discovery and discussion. After a few cases, we switched to our newlyintroduced Microsoft Teams (Microsoft, 2021) environment as we could reach colleagues outside IT better than using Slack. Within Teams, we opened a new group chat for each case, and in addition, we started a Jira (Atlassian, 2021) Board to manage the overview regarding our (concurrent) cases.

The following diagram shows the relationships of the above-mentioned building blocks:

\section{The IT-Cooperation-Model at work}

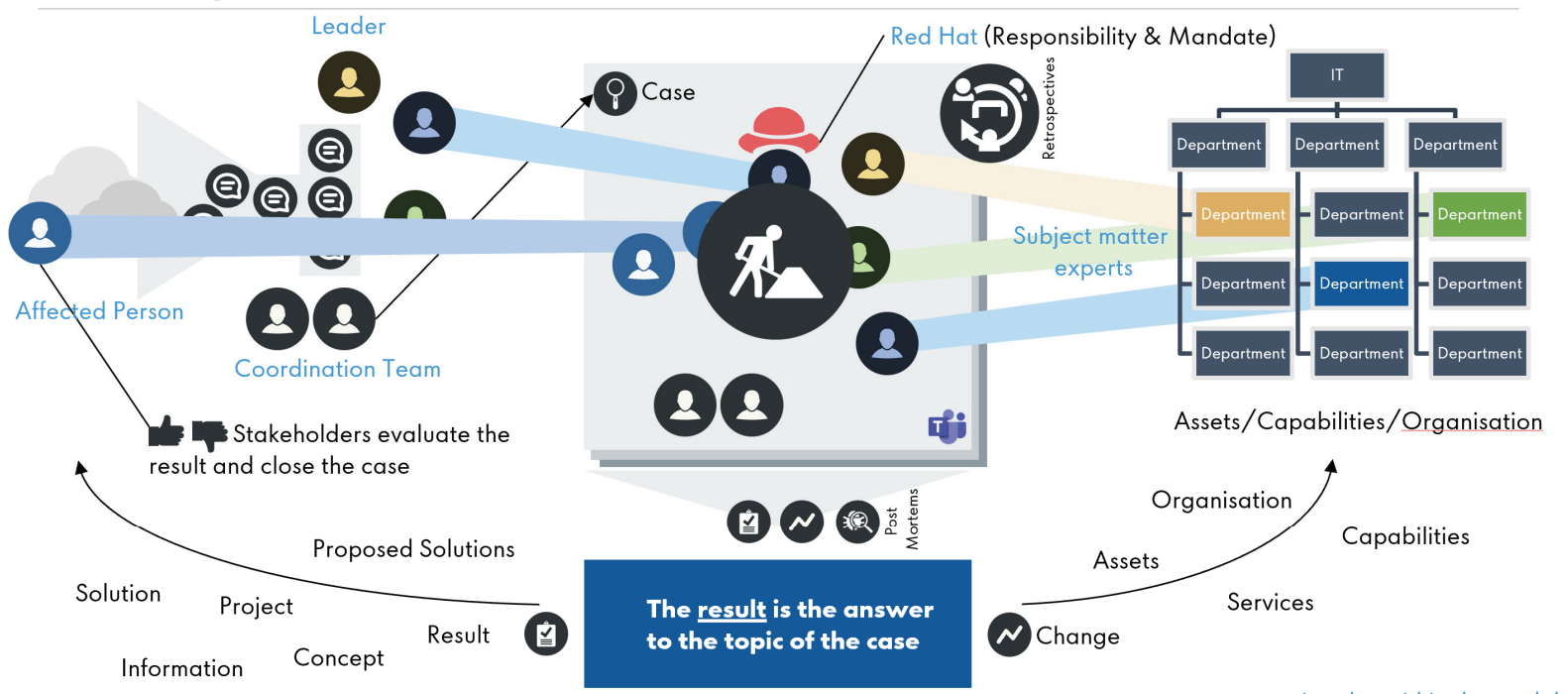

Figure 1: IT-Cooperation-Model with its roles working together on cases

\section{Typical case}

As already assumed when designing the model, there are two main types of cases:

1. The first type is the cleaner cases, which mainly concern faults in the IT systems and are used to eliminate them and subsequently develop a sustainable solution quickly. The characteristic of this type of case is that the higher the impact of a case, the faster it was worked on. This led to the cases becoming an integral part of the mass disruption and problem-solving process.

2. The second main type is the solution design cases. These concern new requirements that cannot be directly located in the IT organisation. The case then develops both a possible solution to the requirement and identifies a unit to implement or operate the solution.

Since the methodology of the cases remains the same, the type of case is irrelevant. The following example is one typical case from more than 300 cases.

\section{Example Case \#236 External Manufacturing}

In the example case, a new production site was built abroad. The space had already been rented, and the production machines were on their way. Various IT service units were accessed selectively via existing processes to request network and telephone systems and clients and servers. The project was managed as a project within the department but was unknown to IT. After a joint meeting between the business department and another IT unit, an IT employee asked for a case to be opened to coordinate the individual IT units. 
The case was opened by a coordination team member based on the information provided by the IT employee, and all known involved and necessary persons were invited to a chat (based on Microsoft Teams). The opening also included a case ID, a short description of the case model with a link to further documentation, a description of the initial situation and objectives, and the question about who can take the Red Hat. Then, the case participants began to share the available information, such as floor plans, addresses and delivery dates, and to retrieve the missing information about the production site directly from the affected person. To ensure that this proceeded in a structured manner, the Red Hat sets up a regular appointment and shared the summary of the appointments in the chat. As soon as it became apparent that other IT units and other affected persons had to contribute, they were added independently by the case participants. As a result, these persons could transparently understand the request and the process by simply reading the chat and supporting or correcting statements made.

It was also helpful that changed delivery dates were identified directly in the case so that every case participant was directly informed.

After the IT equipment was set up, the affected persons gave direct feedback on the individual points, and necessary rework was initiated. When the target was reached, the case could be closed with the agreement of the affected persons.

\section{Discussion}

As the IT-Cooperation-Model was designed as a self-improving model with built-in feedback and improvement loops, we received feedback and improvement ideas from three main sources, as depicted in Table 1.

Table 1: Sources of feedback

\begin{tabular}{|c|c|c|c|}
\hline Source & Description & $\begin{array}{ll}\text { Main } & \text { feedback } \\
\text { provider } & \end{array}$ & $\begin{array}{l}\text { Feedback } \\
\text { type }\end{array}$ \\
\hline Postmortems & $\begin{array}{l}\text { After each closed case, the coordination team } \\
\text { invited the case team to a postmortem to analyse } \\
\text { what we can learn from the case and possibly } \\
\text { improve our IT-Cooperation-Model, Services, } \\
\text { Capabilities or parts of the IT organisation. }\end{array}$ & $\begin{array}{l}\text { Case team, including } \\
\text { the affected person } \\
\text { and the involved } \\
\text { subject matter experts }\end{array}$ & Qualitative \\
\hline Retrospectives & $\begin{array}{l}\text { As the second source for qualitative feedback, the } \\
\text { IT management staff conducted retrospectives to } \\
\text { evaluate and reflect the IT-Cooperation-Model to } \\
\text { regularly discuss the experiences and perceived } \\
\text { room for improvements. }\end{array}$ & IT management staff & Qualitative \\
\hline Survey & $\begin{array}{l}\text { We conducted a survey to reach out to all people } \\
\text { involved in the IT-Cooperation-Model system } \\
\text { (Schlage, Marius, 2021). Here we wanted to } \\
\text { identify how well we improved in our previously } \\
\text { discussed pain points on a quantitative basis (see } \\
\text { Limitations and pain points of existing ITIL-only } \\
\text { approach). }\end{array}$ & $\begin{array}{l}\text { All people involved } \\
\text { in the } 300 \text { cases incl. } \\
\text { non-IT departments }\end{array}$ & Quantitative \\
\hline
\end{tabular}

In the following sections, we discuss the feedback we received so far after over 300 iterations of the model and how it helped us to improve the model. At the same time, we distinguish between the qualitative continuously (postmortems and retrospectives) and quantitative (survey) feedback:

\section{Observations from postmortems and retrospectives}

Considering the major change that the introduction of the model implied for the IT organisation, the reactions, challenges and willingness to comply with the model were diverse. But, overall, 
they were neither particular negative nor positive. Finally, we present the main cluster (Table 2 ), where we encountered notable reactions and interesting mechanics of the model.

\section{Cluster 1: The way of working with the model implies a change in the mindset}

Because of the model's guiding principles (see Guiding principles) and the derived mechanics of the model, the internal customer, colleagues and executives had to adjust to new ways of working. In comparison to a normal chain of command and clear assignments of responsibilities, the case team and its roles (see Roles within the IT-Cooperation-Model) are empowered as a temporary team that stays responsible throughout the whole case. Hence, an executive needs to accept that their employees are invited into cases and are expected to invest time into them. Colleagues used to a classic IT Service Management System with ticket flow, and relatively frequent transfers of responsibilities were confronted with the possibility and necessity to address the case directly and its underlying challenges. The absence of the possibility for a case member to transfer the ticket and the linked responsibility took away their retreat. Every case member in every role had to participate cooperatively in solving the case actively. As described above, the case team must actively gather the information it needs to solve the case. This removes the excuse that the information was not present or accessible. There is no excuse for waiting on someone else's expertise as the case team has the means to let that person directly participate and, furthermore, find that person is part of the casework.

Having the affected person included within the case is beneficial concerning direct and fast feedback, the possibility of clarifying the issue, and continuously keeping the "customer" informed. But with this transparent information, management colleagues also become intimidated and are partly afraid of acknowledging their ignorance. Here we observed several situations of parallel communication outside the main case channel, which led to potentially reduced information flow for the case team.

\section{Cluster 2: Differentiating the cases from common incidents}

The nature of the first cases of the 300 so far were clearly issues that needed direct attention, and there was no appropriate solution to handle them based on our standard processes. However, after the first couple of iterations, we encountered the first cases that had characteristics of normal incidents or issues that were more suited to be resolved by a particular team and did not need the spawned case team to resolve the issue. This sort of case is the side effect of having an extra low threshold with no pre-classification. Nevertheless, the case team always decided whether the case should be continued within the case setting, be transformed into a normal ticket within the IT service management system, or handled in another standard IT process.

\section{Cluster 3: Cases are exhausting}

Even though all problem-solving needs effort, working on cases within the presented ITCooperation-Model mainly costs effort. This is symptomatic for the average case as it needs analysis of the non-trivial root causes as they are non-usual, pre-classified ITIL incidents. Furthermore, working within the case team is necessarily group work. It requires a high amount of synchronous and asynchronous communication, sometimes with many people with distinct backgrounds. This is an issue for SMEs with a skill set that is requested more frequently than usual for casework and who therefore participate in several cases in parallel. This is also true for the members of the coordination team and the IT executives (see Roles within the ITCooperation-Model) participating in several cases. The context switch between the different cases and the absence of detailed process blueprints to follow as guard rails, which would give clear direction and could be followed easily by these case members, make casework exhausting. 


\section{Cluster 4: The growing amount of parallel cases requires prioritisation}

As all case members are also working in their usual departments with their busy day-to-day business, prioritising the cases is obviously an issue. As the first couple of cases were all medium or high priority and the total number of parallel cases was low, the prioritisation between casework and day-to-day business was no issue. However, as time went by and the ITCooperation-Model was also used for cases with lower priority, the colleagues had to decide between investing their capacity into the cases or their day-to-day department work. To better assess the amount of work in the cases, they regularly asked for advice from their Team Lead. Hence, the Team Lead had a lot of additional prioritisation regarding the plannable day-to-day tasks and the ad-hoc cases. As one of the iterative improvements to the model, we introduced a system for prioritising the cases consistently concerning the other incident and ticket tasks for the employees. By this mechanism, every colleague could easily assess if the new case was more, less or just as important as their day-to-day business tasks. This reduced the communication necessity between the case member and Team Lead.

\section{Cluster 5: Finding and using the roles within each case}

The above-defined roles (see Roles within the IT-Cooperation-Model) are necessary for the model to work smoothly and efficiently. On the one hand, we experienced that the roles of the coordination team, the SME and executives were rather quickly filled by suitable colleagues. On the other hand, we observed that the role of the Red Hat was often not taken promptly and that it did not appear to be as powerful as intended in the cases. We observed a few cases where the Red Hat could not motivate the case team to work on the case issue on time. We assume that the Red Hat role was not communicated clearly enough regarding its function and mandate.

Table 2: Listing of observations and their corresponding cluster

\begin{tabular}{|l|l|l|}
\hline Cluster & \multicolumn{2}{|l|}{ Observations } \\
\cline { 2 - 3 } & 1 & Getting used to the change in the chain of command \\
\cline { 2 - 3 } & 2 & Getting used to losing common retreats \\
\cline { 2 - 3 } & 3 & Additional communication outside the case w/o the affected person \\
\hline Differentiation to incidents & 4 & Cases are spawned which could have been an incident \\
\hline Cases are exhausting & 5 & Cases require a high amount of communication and coordination \\
\cline { 2 - 3 } & 6 & Cases are demanding in their solution \\
\cline { 2 - 3 } & 7 & Cases require a high amount of management \\
\hline Prioritisation & 8 & Prioritisation of cases against day-to-day tasks \\
\hline Roles & 9 & Unclear or ineffective Red Hat role \\
\hline
\end{tabular}

\section{The survey in comparison to our improvement areas and pain points}

The survey (Schlage, Marius, 2021) was our quantitative counterpart in the feedback. In particular, it aimed to give us insights into whether and how well we improved in our previous pain points (see Limitations and pain points of existing ITIL-only approach). The research question was: "Is the satisfaction of the current users of the IT-Cooperation-Model given regarding its use, or what are the existing (latent) obstacles?"

Of the 90 questionnaires from participants considered in the evaluation, $21 \%$ had leadership responsibility. Moreover, with a cumulative $64 \%$ of the respondents, well over half of them had been employed for up to five years within the company, $16 \%$ had been with the company for six to ten years, and $20 \%$ had been with the company for more than ten years and therefore could especially relate to the pain points mentioned in Limitations and pain points of existing ITIL-only approach.

The correlation between the number of cases processed and the perceived increasing benefit showed that knowledge about the model could be increased in a targeted manner. However, 
only the number of cases worked on could be confirmed as an indicator for a high perceived benefit; the length of time in the company, for example, probably does not play a role.

The responses from participants with management responsibilities consistently showed greater awareness of the model and its roles. This finding could be essential for the further development of the model, as the values correlate with the likelihood that cases will be created and actively worked on.

It was also possible to refute the negative connotation of working on cases due to the additional work. The additional work and associated bottlenecks had no significant effect on the perceived benefits. About $80 \%$ of the respondents with bottlenecks due to casework ( $\geq 3$, range from 1 to 5) furthermore perceived the cases as helpful (mean 3.41).

About $70 \%$ of the respondents had worked on at least one case (perceived usefulness of the model $=2.84$ ), but only about $20 \%$ on more than eleven (perceived usefulness $=4.18$ ). The finding that there is a significant difference in the perceived usefulness of the cases underlines the importance of widespread communication and sustained transparency of the model.

In summary, the following core statements could be identified:

- First, the model's roles and associated tasks were not sufficiently known across the board.

- There is a discrepancy in the results with/without management responsibility

- The benefits of the model are perceived differently, mainly depending on the number of cases worked on in the past.

The focus of the areas to be improved by the model was based on the pain points identified in Limitations and pain points of existing ITIL-only approach. The areas for improvement shown in Table 3 were derived from these pain points. The fulfilment of these requirements by the model was verified in the conducted survey.

Table 3: Operationalisation of the variables

\begin{tabular}{|c|c|c|c|c|}
\hline & $\begin{array}{l}\text { Aimed } \\
\text { improvement area }\end{array}$ & Operationalisation & $\begin{array}{l}\text { Mean } \\
\text { value* }\end{array}$ & $\begin{array}{l}\text { 95\%-Confidence } \\
\text { Interval }\end{array}$ \\
\hline $\mathrm{r}_{-} 1$ & $\begin{array}{l}\text { direct customer- } \\
\text { integrating } \\
\text { communication/low } \\
\text { threshold }\end{array}$ & $\begin{array}{l}\text { by the restrictions of the model: } \\
\text { - The client is automatically part of the } \\
\text { team } \\
\text { - No threshold (an issue that needs } \\
\text { attention) }\end{array}$ & & \\
\hline $\mathrm{r}_{-} 2$ & transparency & $\begin{array}{l}\text { - I always know the current status of the } \\
\text { cases I am working on. } \\
\text { - I know who to contact with questions, } \\
\text { comments and criticism about a specific } \\
\text { case } \\
\text { - I know what is required of me in a case } \\
\text { and how I can fulfil/achieve it. } \\
\text { - Staff interest in the case overview is high }\end{array}$ & 3.34 & $\begin{array}{l}3.0872<\mu<3.6024 \\
3.4488<\mu<4.0685 \\
3.2783<\mu<3.8252 \\
3.443<\mu<3.9518\end{array}$ \\
\hline r_3 & $\begin{array}{l}\text { cross-team } \\
\text { collaboration/ } \\
\text { autonomous }\end{array}$ & $\begin{array}{l}\text { - I know what is required of me in a case } \\
\text { and how I can fulfil/achieve it. } \\
\text { - I actively seek out missing information } \\
\text { on a case. } \\
\text { - I can control/organise my collaboration } \\
\text { on cases myself. } \\
\text { - I work on finding solutions even without } \\
\text { being prompted by the "Red Hat" role. }\end{array}$ & $\begin{array}{c}3.55 \\
4.09 \\
3.21 \\
4\end{array}$ & $\begin{array}{l}3.2783<\mu<3.8252 \\
3.8486<\mu<4.3238 \\
2.9214<\mu<3.4997 \\
3.8486<\mu<4.3238\end{array}$ \\
\hline$r_{-} 4$ & $\begin{array}{l}\text { ownership/no transfer } \\
\text { of responsibility }\end{array}$ & $\begin{array}{l}\text { - } \quad \text { Staff interest in the case overview is high } \\
\text { - } \quad \text { I work on finding solutions even without } \\
\text { being prompted by the "Red Hat" role. }\end{array}$ & $\begin{array}{c}3.7 \\
4 \\
3.81\end{array}$ & $\begin{array}{c}3.443<\mu<3.9518 \\
3.8486<\mu<4.3238 \\
3.5443<\mu<4.0722\end{array}$ \\
\hline
\end{tabular}




\begin{tabular}{|l|l|l|l|l|}
\hline & $\bullet \begin{array}{l}\text { How likely will you actively work on } \\
\text { cases in the future? }\end{array}$ & \\
\hline
\end{tabular}

About the model's awareness (from $1=$ not at all to $5=$ very much), the results did not allow for any reliable findings, as almost the entire solution space was equally distributed due to the wide standard deviation (1.4). The restrictions of the model may undermine the intended improvement listed under $r$. The probability that one of the respondents would create a case for a challenge correlates with the perceived usefulness of cases $(r=0.6329) .{ }^{2}$ Based on the results of 2.69 (range $1-5$ ) regarding the probability of creating a case in the face of challenges, it is important to promote the cooperation and understanding of the cooperation model to use this tool more comprehensively.

\section{Conclusion and future work}

After over 300 iterations of the model and, therefore, many post mortems and several retrospectives, we conclude that there are still some issues we have to deal with (see Discussion) to improve our model further. Nevertheless, our survey should tell us that we improved in several areas as depicted in Table 4:

Table 4: Improvements in aimed improvement areas

\begin{tabular}{|l|l|}
\hline Improvement area & Improvement \\
\hline Communication & $\begin{array}{l}\text { For the affected persons, the situation has improved because they felt well } \\
\text { informed during the case, including all subject matter experts. As a result, faster } \\
\text { feedback cycles directly in the case were made possible. }\end{array}$ \\
\hline Transparency & $\begin{array}{l}\text { Cases are more visible compared to the ITIL ticket (incident ticket). The person } \\
\text { affected is included and knows about the status. Furthermore, the Red Hat is } \\
\text { named and can be asked about the status and next steps. Unfortunately, side } \\
\text { channels (without the customer/stakeholder) are opened based on perceived } \\
\text { necessity. }\end{array}$ \\
\hline Ownership & $\begin{array}{l}\text { Cases without the role of the Red Hat have not worked. Accountability for the } \\
\text { case and the need to solve the issue is clearly defined with the case and its roles } \\
\text { (accountability lies within the team). The subject matter experts know they must } \\
\text { act and cannot fall into a ticket-ping-pong behaviour. }\end{array}$ \\
\hline Cross-team collaboration & $\begin{array}{l}\text { The relevant subject matter experts from usually different departments are } \\
\text { directly working together in one virtual room. }\end{array}$ \\
\hline
\end{tabular}

From the Pain-Points-view (see Limitations and pain points of existing ITIL-only approach), we did improve most of them. For example, Ticket-ping-pong, separation of problems and incidents (and any other pre-classification), indirect communication and proxy functions of service management were eliminated within the case model through the guiding principles. Only the misguiding incentives are still an issue, as preventing something proactively before it has a negative impact still leaves your performance unproven and low visibility.

With the IT-Cooperation-Model, we were able to find an alternative and improved approach to our ITIL problem, incident and requirements management processes, and handling relevant issues that do not fit in one of these standard processes. We can react to our "cases" - topics that need attention and cannot be dealt with immediately or addressed appropriately. Some of the challenges we encounter today following the IT Cooperation Model were present in the previous time, but now we can discuss them transparently. We believe that overcoming the discussed challenges is worth the effort and that we will continuously receive motivating and relevant feedback to improve our model further. We want to increase the amount of feedback we receive by implementing an integrated satisfaction survey within the case closing phase and want to put a particular focus on solving the root cases and not only the symptoms.

\footnotetext{
${ }^{2}$ Pearson correlation coefficient
} 


\section{References}

Anand, G., Ward, P. T., Tatikonda, M. V., \& Schilling, D. A. (2009). Dynamic capabilities through continuous improvement infrastructure. Journal of Operations Management, 27(6), 444-461. https://doi.org/10.1016/j.jom.2009.02.002

Anderson, D. J. (2003). Agile Management for Software Engineering: Applying the Theory of Constraints for Business Results. Prentice-Hall Professional.

Atlassian. (2021). Jira | Issue \& Project Tracking Software. Atlassian. https://www.atlassian.com/software/jira

AXELOS. (2011). ITIL Glossary and abbreviations.

Becker, J., \& Kahn, D. (2011). The Process in Focus. In J. Becker, M. Kugeler, \& M. Rosemann (Hrsg.), Process Management. A Guide for the Design of Business Processes (2. Aufl., S. 3-14). Springer-Verlag Berlin Heidelberg.

Becker, J., \& Schütte, R. (2004). Handelsinformationssysteme: Domänenorientierte Einführung in die Wirtschaftsinformatik (2. Aufl.). Redline Wirtschaft.

Bessant, J., \& Caffyn, S. (1997). High-Involvement Innovation Through Continuous Improvement. International Journal of Technology Management - INT J TECHNOL MANAGE, 14. https://doi.org/10.1504/IJTM.1997.001705

Birk, A., Dingsøyr, T., \& Stålhane, T. (2002). Postmortem: Never leave a project without it. Software, IEEE, 19, 43-45. https://doi.org/10.1109/MS.2002.1003452

BMC. (2021, November 13). ITIL Incident Management: An Introduction. BMC Blogs. https://www.bmc.com/blogs/itil-v3-incident-management/

COBIT. (2021, January 14). ISACA Germany Chapter e. V. https://www.isaca.de/de/veroeffentlichungen/cobit

den Hengst, M., \& de Vreede, G. (2004). Collaborative Business Engineering: A Decade of Lessons from the Field. Journal of Management Information Systems, 20(4), 85-113.

Edmondson, A. (1999). Psychological Safety and Learning Behavior in Work Teams. Administrative Science Quarterly, 44(2), 350-383. https://doi.org/10.2307/2666999

Hammer, M. (2010). What is Business Process Management? In J. vom Brocke \& M. Rosemann (Hrsg.), Handbook on Business Process Management: Introduction, Methods, and Information Systems (S. 3-16). Springer Berlin Heidelberg. https://doi.org/10.1007/978-3-642-00416-2_1

ISO.

(2011). 20000-1:2011.

ISO. https:/www.iso.org/cms/render/live/en/sites/isoorg/contents/data/standard/05/19/51986.html

it-processmaps. (2020). ITIL Processes | IT Process Wiki. IT Process Wiki - the ITIL® Wiki. https://wiki.en.itprocessmaps.com/index.php/ITIL_Processes

Juric, R. (2000). Extreme programming and its development practices. 97-104.

Kaymaz, K. (2011). Performance Feedback: Individual-Based Reflections and the Effect on Motivation. Business and Economics Research Journal, 2(4), 115-134.

Ken Schwaber, \& Jeff Sutherland. (2020). Scrum Guide | Scrum Guides. https://scrumguides.org/scrumguide.html

Markey-Towler, B. (2017). Narratives and Chinese Whispers: Ideas and knowledge in bubbles, diffusion of technology and policy transmission. https://doi.org/10.13140/RG.2.2.22737.12642

Microsoft. (2021). Microsoft Teams. Microsoft Teams Boost Teamwork in Your Business for Free. https://www.microsoft.com/en-us/microsoft-teams/free

Peter Schneider \& Philip Scherer. (2020, März 10). ITSM-Methoden: ITIL V4 Hands-on. ITIL V4 Hands-on. https://www.computerwoche.de/a/itil-v4-hands-on,3548446

Peter Van den Spiegel, Leen Dieltjens, \& Liese Blevi. (2013). BPI Challenge 2013-Applied process mining techniques for incident and problem management. In Boudewijn van Dongen, Barbara Weber, Diogo Ferreira, \& Jochen De Weerdt (Hrsg.), Proceedings of the 3rd Business Process Intelligence Challenge (BPIC 2013). http://ceur-ws.org/Vol-1052/paper12.pdf 
Richardson, G. P., \& Andersen, D. F. (1995). Teamwork in group model building. System Dynamics Review, 11(2), 113-137.

Sandhu, R. S., Coyne, E. J., Feinstein, H. L., \& Youman, C. E. (2002). Role-based access control models. Computer, 29(2), 38-47.

Schlage, Marius. (2021). First survey on the operations model 2021.

Slack Technologies. (2021). Where work happens. Slack. https://slack.com/

What is ITIL | IT service management? (2021). AXELOS. https://www.axelos.com/best-practicesolutions/itil/what-is-itil 